\title{
Analyst
}

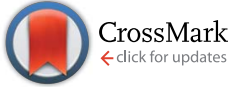

Cite this: Analyst, 2014, 139, 6058

\section{Correction: Spatial organization of Pseudomonas aeruginosa biofilms probed by combined matrix- assisted laser desorption ionization mass spectrometry and confocal Raman microscopy}

\author{
Rachel N. Masyuko, ${ }^{a}$ Eric J. Lanni, ${ }^{b}$ Callan M. Driscoll, ${ }^{c}$ Joshua D. Shrout, ${ }^{c}$ \\ Jonathan V. Sweedler ${ }^{\star b}$ and Paul W. Bohn*ad
}

DOI: $10.1039 / c 4 a n 90079 k$

Correction for 'Spatial organization of Pseudomonas aeruginosa biofilms probed by combined matrixassisted laser desorption ionization mass spectrometry and confocal Raman microscopy' by Rachel N.

www.rsc.org/analyst

Masyuko et al., Analyst, 2014, DOI: 10.1039/c4an00435c.

In the original study for the DOI detailed above, Masyuko et al. examined the Raman and mass spectrometric microspectra and images accompanying transition from planktonic cells to biofilms in wild-type Pseudomonas aeruginosa and in a quorum sensing (QS)-deficient mutant, AlasI $\Delta r h l I$. In the course of follow-up studies, we became aware that some of the Raman spectra attributed to wild-type biofilm could have arisen from a contaminant, microparticulate polystyrene (PS). Subsequently, a new series of wild-type Pseudomonas biofilms were grown under rigorously PS-free conditions, and new spectra and images were acquired. For the new data shown in the figures below, Fig. 1 replaces the spectrum shown in Fig. 1(b) of the original and Fig. 3 replaces the images shown in Figs. 3(b) and S2 of the original. A detailed consideration of the bands and their assignments in the new biofilm spectrum is given in the Supplemental Information (see below).

While detailed analysis of the biofilm spectrum, Fig. 1(b), and the image acquired, Fig. 3(b), differ from the corresponding data in the original, the major conclusions of the paper are unaffected. In particular:

(1) the wild-type biofilm spectra are markedly different than the corresponding wild-type planktonic cell spectra, $c f$. Fig. 1(b) vs. Fig. 1(a);

(2) wild-type biofilms produce spectra that are characteristic of rhamnolipids, secreted as part of the biofilm formation process, and by a co-secreted protein/peptide component; and

(3) these data are consistent with the formation of a thick (relative to the sampling depth of the CRM) biofilm after $72 \mathrm{~h}$ in the wild type cells, but not in the QS mutant.

\section{Supplemental Information}

Text in the original describing the Raman spectra (Figs. 1(b) and 3(b) in the original) should be replaced with the following.

Upon biofilm formation, dramatic changes occur in the spectrum, Fig. 1(b). Biofilms cultivated on bare Si exhibit a greatly reduced $\mathrm{SiO}_{2}$ background (915-1015 $\mathrm{cm}^{-1}$ ), presumably because biofilms at $72 \mathrm{~h}$ are much thicker than the $<1 \mu \mathrm{m}$ confocal depth of the CRM. In addition, the strong DNA/RNA-related bands at 747 (thymine), 1126 (cytosine), and $1310 \mathrm{~cm}^{-1}$ (adenine) are all diminished in relative intensity. The strong band at $1585 \mathrm{~cm}^{-1}$ is reduced in strength and a new band at $1606 \mathrm{~cm}^{-1}$ grows in. In addition, narrow bands with peaks centered at $1005 \mathrm{~cm}^{-1}$ and $1034 \mathrm{~cm}^{-1}$ appear as well as bands centered at $830 \mathrm{~cm}^{-1}, 1166 \mathrm{~cm}^{-1}$, $1186 \mathrm{~cm}^{-1}, 1417 \mathrm{~cm}^{-1}, 1445 \mathrm{~cm}^{-1}$ and $1558 \mathrm{~cm}^{-1}$. Most striking is the intense peak at $1005 \mathrm{~cm}^{-1}$ attributed to symmetric ring breathing vibrations in phenylalanine and tryptophan, indicative of proteins. ${ }^{1}$ Other bands characteristic of proteins are at 830 $\mathrm{cm}^{-1}$ ring breathing vibrations in tyrosine (with a possible contribution from rhamnolipid), $1186 \mathrm{~cm}^{-1}$ arising from C-H in plane bending vibrations in tyrosine and phenylalanine, ${ }^{2} 1214 \mathrm{~cm}^{-1}$ and $1246 \mathrm{~cm}^{-1}$ both assigned to amide III vibrations, $1558 \mathrm{~cm}^{-1}$ linked to the $\mathrm{C}-\mathrm{C}$ pyrrole ring stretching vibrations in tryptophan and the two bands at $621 \mathrm{~cm}^{-1}$ and $1605 \mathrm{~cm}^{-1}$ arising from in plane ring deformation and $\mathrm{C}=\mathrm{C}$ stretching vibrations in phenylalanine, respectively. ${ }^{1}$

${ }^{a}$ Department of Chemistry and Biochemistry, University of Notre Dame, Notre Dame, IN 46556, USA. E-mail: pbohn@nd.edu

${ }^{b}$ Department of Chemistry, University of Illinois at Urbana-Champaign, 600 S. Mathews Ave., Urbana, IL 61801, USA. E-mail: jsweedle@illinois.edu

${ }^{c}$ Department of Civil and Environmental Engineering and Earth Sciences, University of Notre Dame, Notre Dame, IN 46556, USA

${ }^{d}$ Department of Chemical and Biomolecular Engineering, University of Notre Dame, Notre Dame, IN 46556, USA 


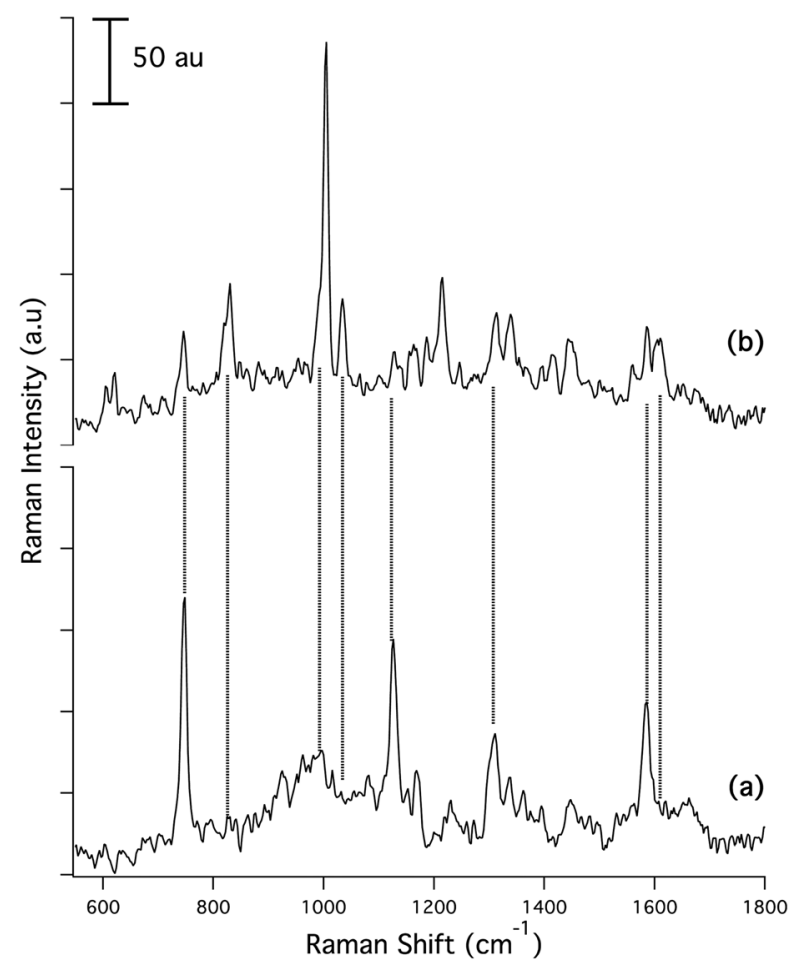

Fig. 1 Raman microspectra of wild type Pseudomonas aeruginosa. (a) Planktonic cells, as deposited on Au-coated Si substrate. (b) Biofilm after $72 \mathrm{~h}$ formation on uncoated Si. Raman spectra are baseline corrected using a fourth order polynomial function. Vertical dashed lines added to aid comparison between spectra. Spectrum $1(a)$ is identical to that in the original.

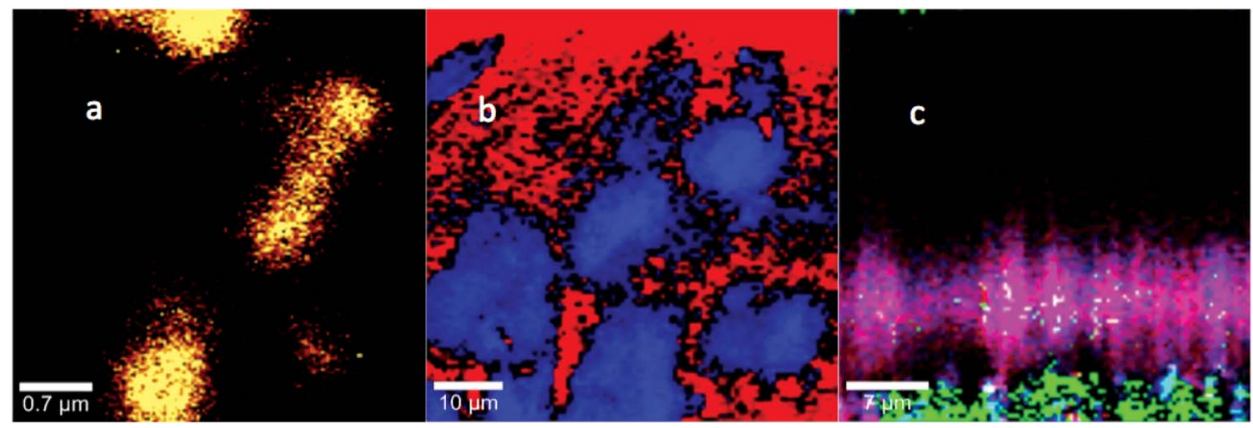

Fig. 3 Composite Raman images of different Pseudomonas aeruginosa samples. (a) Plan view image of planktonic cells constructed from scattering in the region $2800-3050 \mathrm{~cm}^{-1}$. Scale bar $0.7 \mu \mathrm{m}$. (b) Plan view image of a biofilm constructed from a combination of bands in the regions $2800-3050 \mathrm{~cm}^{-1}$ (red) and $980-1020 \mathrm{~cm}^{-1}$ (blue), representing all organic components and protein scattering, respectively. Scale bar $10 \mu \mathrm{m}$. (c) Depth profile of the biofilm in the $x-z$ plane constructed from $2800-3050 \mathrm{~cm}^{-1}$ (red), $1560-1620 \mathrm{~cm}^{-1}(\mathrm{blue}) \mathrm{and} 725-775 \mathrm{~cm}^{-1}$ (green). Scale bar $7 \mu \mathrm{m}$. Panels (a) and (c) are identical to those in the original.

The important band at $1034 \mathrm{~cm}^{-1}$, as well as bands at $1129 \mathrm{~cm}^{-1}$ and $1163 \mathrm{~cm}^{-1}$, lie in the carbohydrate region of the spectrum, and are observed in the wild-type biofilm spectrum, Fig. 1(b), but not in the spectrum from the planktonic cells, Fig. 1(a). These are classified as $\mathrm{C}-\mathrm{O}$ stretching with contributions from in plane $\mathrm{C}-\mathrm{H}$ deformations in phenylalanine $\left(1034 \mathrm{~cm}^{-1}\right), \mathrm{C}-\mathrm{C}$ and $\mathrm{C}-\mathrm{O}$ symmetric $\left(1128 \mathrm{~cm}^{-1}\right)$ and asymmetric $\left(1163 \mathrm{~cm}^{-1}\right)$ ring breathing vibrations. ${ }^{3-5}$ In the context of Pseudomonas-derived biofilms, these bands are consistent with the presence of rhamnolipids, ${ }^{6}$ a specific class of glycolipids known to be secreted by Pseudomonas species concurrently with biofilm formation, ${ }^{7,8}$ an assignment confirmed via MS. Comparison of representative microspectra from a Pseudomonas wild-type biofilm, Fig. 1(b) with a mixed rhamnolipid standard shows that the standard has contributions from common Raman bands at $1030 \mathrm{~cm}^{-1}, 1068 \mathrm{~cm}^{-1}$, and $1155 \mathrm{~cm}^{-1}$ (wide band that includes the contributions at $1163 \mathrm{~cm}^{-1}$ ) characteristic of the sugar moieties, as well as a strong band at $1445 \mathrm{~cm}^{-1}$ as described above consistent with the presence of 
Table S1 Raman band assignments for $P$. aeruginosa biofilm spectrum

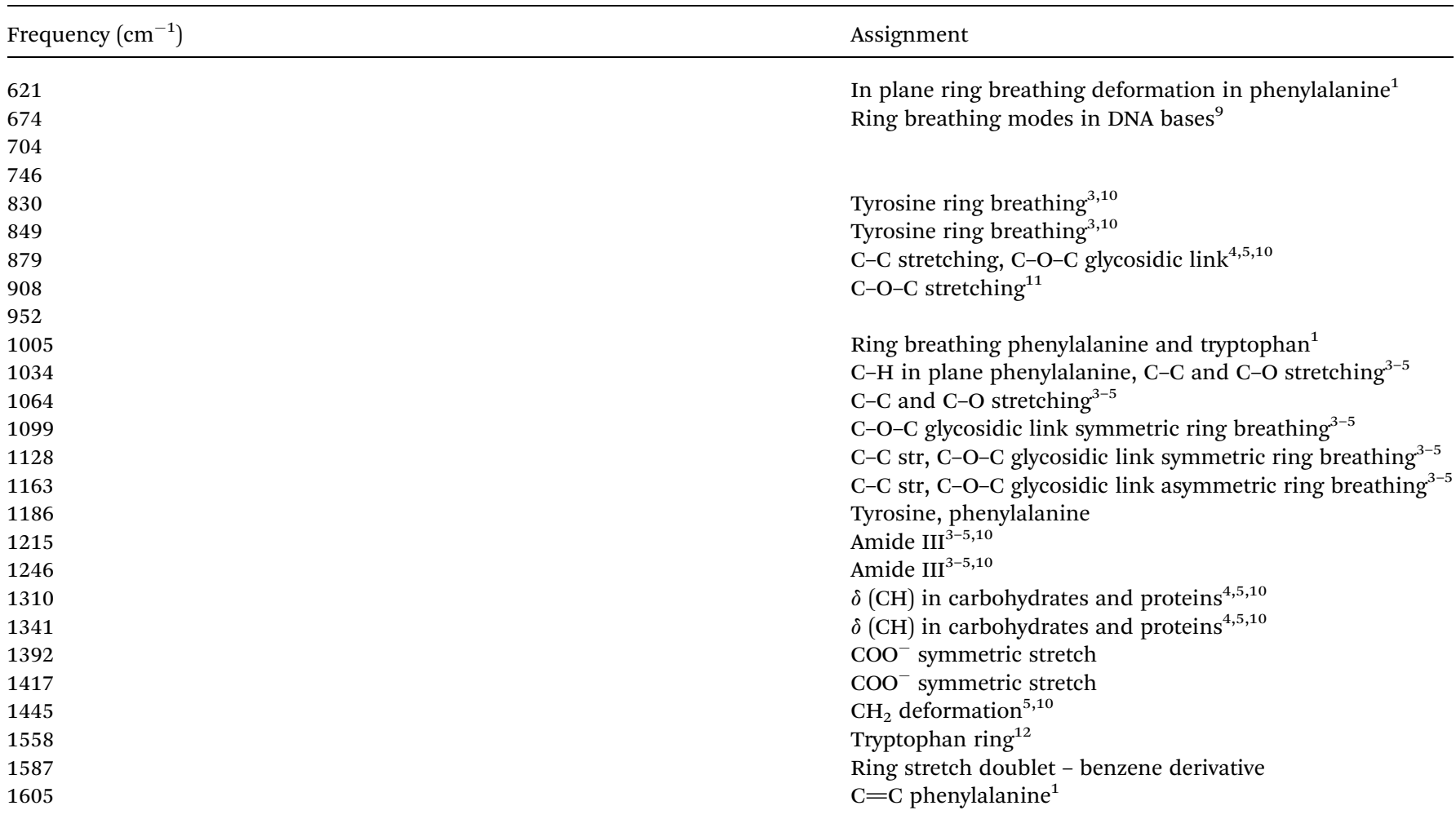

rhamnolipids in the biofilm matrix. Confirming the assignment of these bands to rhamnolipids, the MS data not only show the presence of rhamnolipids, but also allow their assignment to individual congeners.

Band assignments for the biofilm spectrum are summarized in Table S1.

\section{References}

1 G. J. Puppels, H. S. P. Garritsen, G. M. J. Segersnolten, F. F. M. Demul and J. Greve, Biophys. J., 1991, 60, $1046-1056$.

2 N. Uzunbajakava, A. Lenferink, Y. Kraan, B. Willekens, G. Vrensen, J. Greve and C. Otto, Biopolymers, 2003, 72, 1-9.

3 I. Notingher, S. Verrier, H. Romanska, A. E. Bishop, J. M. Polak and L. L. Hench, Spectrosc. Int. J., $2002,16,43-51$.

4 M. Harz, P. Rosch, K. D. Peschke, O. Ronneberger, H. Burkhardt and J. Popp, Analyst, 2005, 130, $1543-1550$.

5 U. Neugebauer, U. Schmid, K. Baumann, W. Ziebuhr, S. Kozitskaya, V. Deckert, M. Schmitt and J. Popp, ChemPhysChem, 2007, 8, 124137.

6 M. Jadhav, S. Kalme, D. Tamboli and S. Govindwar, J. Basic Microbiol., 2011, 51, 385-396.

7 B. R. Boles, M. Thoendel and P. K. Singh, Mol. Microbiol., 2005, 57, 1210-1223.

8 M. E. Davey, N. C. Caiazza and G. A. O'Toole, J. Bacteriol., 2003, 185, 1027-1036.

9 J. W. Chan, D. S. Taylor, T. Zwerdling, S. M. Lane, K. Ihara and T. Huser, Biophys. J., 2006, 90, 648-656.

10 K. Maquelin, C. Kirschner, L. P. Choo-Smith, N. van den Braak, H. P. Endtz, D. Naumann and G. J. Puppels, J. Microbiol. Methods, 2002, 51, 255-271.

11 J. De Gelder, K. De Gussem, P. Vandenabeele, M. Vancanneyt, P. De Vos and L. Moens, Anal. Chim. Acta, 2007, 603, 167-175.

12 J. T. Pelton and L. R. McLean, Anal. Biochem., 2000, 277, 167-176.

The Royal Society of Chemistry apologises for these errors and any consequent inconvenience to authors and readers. 